\title{
Generic isotretinoin: a new risk for unborn children
}

\author{
Gideon Koren, Marina Avner, Neil Shear
}

$\mathrm{T}$

he introduction of isotretinoin (Accutane) in 1982 was a milestone in the treatment of recalcitrant nodular acne. Although the severe teratogenic effects of the drug quickly became evident, ${ }^{1}$ its use rapidly increased and was inappropriately extended to patients with less severe forms of acne., ${ }^{2,3}$ Of 1000 patients who participated in an international survey in 1997, $45 \%$ did not have the labelled indication for the drug. ${ }^{4}$ Also, new off-label uses have emerged, including treatment of dermatologic conditions such as gram-negative folliculitis, recalcitrant rosacea, pyoderma faciale, generalized lichen planus, psoriasis, cutaneous lupus erythematosus and acne fulminans ${ }^{5}-$ as well as, more recently, the treatment of squamous cell carcinomas ${ }^{6}$ and leukemias.

Pre-market studies in animals showed high rates of central nervous system and facial malformation after gestational exposure; indeed, within months of the introduction of isotretinoin into the market, severe malformations reported in infants of women taking the drug revealed that it is a potent human teratogen. ${ }^{8}$ Box 1 presents the features of isotretinoin embryopathy. About $40 \%$ of infants exposed to isotretinoin in the first trimester will have major malformations. In addition, children exposed in utero who are spared from major malformation may still be affected by cognitive deficits.

In 1988 the US Food and Drug Administration (FDA) and the manufacturer of Accutane (Roche) developed a Pregnancy Prevention Program aimed at increasing women's awareness of the teratogenicity of the drug and of the importance of preventing conception. ${ }^{9}$ This program called for women to give written informed consent and commit to using 2 contraceptive methods simultaneously while taking isotretinoin therapy (see Box 2). This program was adopted by Health Canada soon after.

In spite of these efforts, reports of fetal exposure continued to accumulate through the 1990s. ${ }^{10}$ As a result, in 2002 the Pregnancy Prevention Program was modified to include additional measures (see Box 3) and was renamed SMART (System to Manage Accutane Related Terato-

\section{Box 1: Characteristics of isotretinoin embryopathy}

- Central nervous system: microcephaly with hydrocephaly

- Face and head: absence or reduced size of outer ear and ear canal

- Heart: defect of aortic arch, double outlet of right ventricle

- Thymus: hypoplasia, aplasia
Box 2: Components of the Pregnancy Prevention Program for isotretinoin ${ }^{9}$

- Information brochure for patients

- Product monograph for patients and physicians

- Qualification checklist for placing women of childbearing potential on isotretinoin and concurrent birth control

- Verbal information for patients

- Consent-to-treatment form

- Line drawing representing common birth defects associated with isotretinoin use in pregnancy

- Restrictions on prescribing the drug unless the patient has severe, disfiguring acne unresponsive to standard therapies or severe intractable psoriasis, keratosis follicularis, ichthyosis dermatoses or palmoplantar pustulosis

- Determination that the patient is reliable in executing instructions

- Negative serum pregnancy test 2 weeks before initiation of therapy

- Verbal and written warnings to avoid pregnancy during isotretinoin therapy and for 2 months after cessation of therapy

genicity). ${ }^{11}$ The SMART program has not been adopted in Canada.

At the outset, the FDA indicated that, if SMART did not succeed in reducing gestational exposures to isotretinoin, additional restrictions would be imposed on the drug. In February 2004, an FDA advisory committee recommended that, in view of continuing safety issues, a mandatory registration for isotretinoin users and prescribers should be implemented. ${ }^{12}$

The expiry of the patent exclusivity of Accutane has opened up a lucrative market, prompting the rapid introduction of 3 generic forms of the drug in the United States: Amnesteen (November 2002), Sotret (December 2002) and Claravis (April 2003). Over 30 generic forms of isotretinoin are now available internationally. Currently, several manufacturers are considering the introduction of generic isotretinoin in Canada.

As part of the Motherisk program, we have been monitoring isotretinoin use since 1991. Between January 2002 and December 2003, we received 11 calls from women who had become pregnant while taking Accutane. Of these, only 4 had recalcitrant nodular acne, the only indication approved by Health Canada. A similar trend continues in the United States, where only 2 of 11 cases collected in 2003 by the Organization of Teratology 
Information Services had the labelled indication.

Moreover, although the drug was originally intended to be prescribed by dermatologists, many family physicians now prescribe it. Of the 11 Canadian women who consulted Motherisk, only 5 had a prescription written by a dermatologist, only 5 had seen printed information on the Pregnancy Prevention Program, and only 2 had signed a consent form. Only 1 of the 11 reported using 2 forms of contraception, yet 10 of the women had been warned verbally about fetal risk. Of the 5 prescriptions written by dermatologists, only 3 were for recalcitrant nodular acne.

The introduction of generic forms of isotretinoin, together with decreasing prices, will further increase the use of this drug by sexually active young women. It is also evident that the means used to avert the tremendous teratogenic risk of isotretinoin have not been effective. If, 20 years after the drug's introduction in clinical use, cases of fetal exposure continue to be reported, we see little reason to believe that the SMART program will be sufficient to reverse this trend. The flooding of the market with new and cheaper forms of generic isotretinoin is likely to endanger the lives of many more unborn Canadian babies. We need to take steps to protect the unborn from irresponsible prescribing; simply warning women (and their partners) about fetal risk is not enough.

We propose that certification and registration be required for physicians who wish to prescribe isotretinoin. Certification would entail a brief training program that covers the dos and don'ts of prescribing, followed by successful completion of a test. Training can be offered as CME in accredited institutions or through the Internet. Successful Web-based programs of this kind do exist. For example, US researchers who wish to be involved in publicly funded research involving humans must pass the NIHinitiated test on bioethics. ${ }^{13}$

A registration program works very well with respect to methadone prescribing in many countries, including Canada, the United Kingdom, Israel, France and Australia. ${ }^{14}$ The administration of such a program for isotretinoin could be handled provincially by pharmacists' organization, colleges of physicians or other suitable or-

\section{Box 3: SMART requirements}

The System to Manage Accutane Related Teratogenicity (SMART) enhances the Accutane Pregancy Prevention

Program with the following requirements:

- Two negative pregnancy test results before first prescription

- Pregnancy tests repeated monthly during therapy

- Accutane Qualification Sticker affixed to the prescription form to confirm the prescriber's authorization to prescribe isotretinoin and the patient's eligibility to receive it

- Maximum 30-day supply

- No automatic refills ganizations. As part of this new strategy, Internet sales of the drug should be prohibited. In parallel, it would make sense to involve more meaningfully the pharmacists who dispense isotretinoin, who should present to female patients verbal and printed instructions that reinforce the information given by physicians.

One may argue that certification for isotretinoin prescription is not justified, as many other medications can have severe adverse effects. However, irresponsible prescribing of isotretinoin damages innocent fetuses who did not consent to exposure. The proposed program is easy to implement and can help to prevent irreparable, life-long damage to unborn children. We urge Health Canada, the manufacturers, physicians, pharmacists and their associations to adopt this initiative.

This article has been peer reviewed.

From the Motherisk program, Division of Clinical Pharmacology, The Hospital for Sick Children and Sunnybrook and Women's College Health Sciences Centre and the University of Toronto, Toronto, Ont.

Competing interests: Neil Shear has received educational grants from HoffmanLa Roche.

Contributors: Gideon Koren initiated, coordinated and wrote the commentary. Marina Avner conducted the study in the Motherisk program and reviewed the literature. Neil Shear was responsible for the dermatology aspects of this commentary.

Acknowledgement: Dr. Koren is a Senior Scientist with the Canadian Institute for Health Research. His work is supported in part by Jonathan's Allert, The Hospital for Sick Children, Toronto, Ont.

\section{References}

1. Adverse effects with isotretinoin. FDA Drug Bull 1983;13:21-2.

2. Shear NH. Oral isotretinoin: prescribers beware. CMA7 1999;160(12):1723-4.

3. Wysowski DK, Swann J, Vega A. Use of isotretinoin (Accutane) in the United States: rapid increase from 1992 through 2000. 7 Am Acad Dermatol 2002;46: 505-9.

4. Cunliffe WJ, van de Kerkhof PC, Caputo R, Cavicchini S, Cooper A, Fyrand OL, et al. Roaccutane treatment guidelines: results of an international survey. Dermatology 1997;194(4):351-7.

5. Ortonne JP. Oral isotretinoin treatment policy. Do we all agree? Dermatology 1997;195(Suppl 1):34-7.

6. Wieder R, Pavlick AC, Bryan M, Hameed M, Baredes S, Pliner L, et al. Phase I/II trial of accutane as a potentiator of carboplatin and paclitaxel in squamous cell carcinoma. Am 7 Clin Oncol 2002;25(2):447-50.

7. Reynolds CP, Lemons RS. Retinoid therapy of childhood cancer. Hematol Oncol Clin North Am 2002;15:867-910.

8. Lammer EJ, Chen DT, Hoar RM, Agnish ND, Benke PJ, Braun JT, et al Retinoic acid embryopathy. N Engl 7 Med 1985;313(14):837-41.

9. Roche Canada. Information for the consumer. Available: www.rochecanada .com/pdf/Accutane\%20PI\%20E.pdf (accessed 2004 Apr 21).

10. Pastuszak AP, Koren G. The retinoid pregnancy prevention program. Koren G, editor. In: Retinoids in clinical practice: the risk-benefit ratio. New York: Marcel Dekker; 1993. p. 147-76.

11. Lowenstein EJ. Isotretinoin made S.M.A.R.T. and simple. Cutis 2002;70:115-20.

12. Elliott VS. FDA panel back patient registry for acne drug. AMNews 2004 Mar 22/29. Available: www.ama-assn.org/amednews/2004/03/22/hlsc0322.htm\#w1 (accessed 2004 Apr 17).

13. National Institutes of Health. Human participant protections education for research teams. Bethesda (MD): The Institutes; 2002. Available: http://69.5.4 $.33 / \mathrm{c} 01 /$ (accessed 2004 Apr 17).

14. Bell J, Dru A, Fischer B, Levit S, Sarfraz MA. Substitution therapy for heroin addiction. Subst Use Misuse 2002;37:1149-78.

Correspondence to: Dr. Gideon Koren, Division of Clinical Pharmacology, The Hospital for Sick Children, 555 University Ave., Toronto ON M5G 1X8; fax 416 813-7562,

gkoren@sickkids.ca 